\title{
Validation of Design of Regular Carbon Fabric Composite Plate with Woven Fabric using Tensile Loading
}

\author{
Sushma D. Thorat*, V. S. Mahajan \\ Department of Mechanical Engineering, JSPM's RSCOE, Tathawade, Pune
}

(Received 01 August 2020, accepted 18 December 2020)

https://doi.org/10.36224/ijes.130404

\begin{abstract}
In many recent years the use of composite materials increases in many fields, for example agricultural uses, where these materials are characterized by good mechanical properties, tenacity and light weight. Among many other materials for the reinforcement of composites, technical fabrics are increasingly being used for the same purpose, especially from carbon fiber, which have good mechanical properties. During tensile stress these fabrics are elongated in the direction of tensile force, and at the same time they contract crosswise in relation to the action of the tensile force. In this Project the tensile properties of regular carbon fabrics and woven fabrics made from carbon fiber yarns were investigated. Static structural analysis of Regular carbon fabrics and woven fabrics base carbon fiber specimen will be done using ACP tool in ANSYS 19 software.
\end{abstract}

Keywords: Composite materials, FEM Modelling, ANSYS, Woven composite

\section{Introduction}

Composite sections are generally used where there is a requirement for a high strength/stiffness to weight ratio, because their properties can be tailored to specific structural requirements. The anisotropy of composites offers a significant enhancement in their performance over conventional materials. Traditionally, fiber-reinforced composites formed from several layers of unidirectional (UD) tapes pre impregnated with a matrix material are used due to their excellent mechanical properties, such as high specific stiffness and high strength. However, laminated composite plates, which offer good in-plane properties, are proneto delamination due to their poor mechanical properties in the thickness direction. In an attempt to overcome this drawback, woven-fabric (WF) composites, also termed textile composites, are put to use, as they offer a 3D reinforcement in a single layer and provide better mechanical properties in both in-plane and transverse directions. Textile composites find application in many branches of industry thanks to their balanced mechanical properties [1], easy handling, and impact resistance [2].The prediction of elastic properties of textile composites has been an active area of research in the past two decades, because the issues related to such parameters as fiber architecture, matrix properties, and fiber properties [3], affecting the mechanical characteristics of the composites, are highly complex. These factors make the modeling aspect of textile composites extremely challenging. Various assumptions were made by many researchers in the past to cope with the task. The rule of mixture, composite cylinder models, and boundary variation methods [4] are various techniques which provide approximate estimates for the mechanical properties of the composites, but they are limited to a simple geometry and cannot be applied to complex fiber architectures. Therefore, 
new analytical models are needed to effectively predict the mechanical behavior of textile composites and numerical techniques, such as the FEM, are also required to verify the validity of the models.

Textile composites made of woven fabrics have demonstrated excellent mechanical properties for the production of high specific-strength products. Research efforts in the woven fabric sheet forming are currently at a point where benchmarking will lead to major advances in understanding both the strength sand the limitations of existing experimental and modeling approaches. Test results can provide valuable information for the material characterization and forming process design of woven composites if researchers know how to interpret the results obtained from varying test methods appropriately. An international group of academic and industry researchers has gathered to design and conduct bench-marking tests of interest to the composite sheet forming community. Shear deformation is the dominative deformation mode for woven fabrics in forming; therefore, trellis-frame (picture-frame) and bias extension tests for both balanced and unbalanced fabrics have been conducted and compared through this collaborative effort.

\section{Objectives}

i. To understanding the strengths and the limitations of existing laminated composite carbon fibre.

ii. Tensile properties of Regular carbon fabrics and woven fabrics made from carbon fibre yarns were investigated.

iii. To perform Static structural analysis of Regular carbon fabrics and woven fabrics made from carbon fibre specimen using ACP tool in ANSYS 19 software. And comparing the results.

\section{Literature Review}

Modelling the mechanical properties of textile-reinforced composites with a near micro-scale approach by Oliver Döbrich, Thomas Gereke, Chokri Cherif [1]. This paper gives information about the mechanical properties of composite material. The performance of composite materials mainly depends on the mechanics of the embedded reinforcement structure. The reinforcements of composed fibres such as glass or carbon are important in high-performance composites, for the purpose of light weight. Structural designing, the mechanical data of the composite material is considered for structural designing of the optimal light weight. It is cost intensive step to determine of these properties of composite. Author carried out the convergence analyses and they use textile model directly to build up a virtual composite model suitable for virtual mechanical tests. After the study they do the comparison of simulation and testing results which shows very good agreement of the introduced approach with the reality and suggests its further application.

Modelling of textile composites with fibre strength variability by M.Y. Matveev, A.C. Long, I.A. Jones [2]. In this paper author analyse fibre strength variability numerically from micro to macro-scale and consider the size effect and its transition between scales. Scatter in composite mechanical properties is related to variability's occurring at different scales. Author discusses two micro-mechanical models based on the Weibull distribution for mesoscale finite element models of fibre bundles and this result are validated against experimental results. After that these models are then implemented in a meso scale model of an AS4 carbon fibre 
plain weave/vinyl ester textile composite. From the study it is concluded that Monte Carlo simulations shows the fibre strength variability which has a limited effect on the strength of the textile composite at the meso scale and introduces variability of less than $2 \%$ from the mean value. Result obtain from this study are Macro scale strength based on the predicted meso scale distribution is lower than the strength of the composite without variability by $1-4 \%$ depending on the model.

Comparison Mechanical Properties for Fabric (Woven and Knitted) Supported by Composite Material by Karnoub A, Makhlouf S, Kadi N and Azari Z [3]. In this paper author focuses on the use of composite materials reinforced by knitted fabric compared with composite materials reinforced by woven fabric. In many recent years the use of composite materials increases in many fields, for example agricultural uses, where these materials are characterized by good mechanical properties, tenacity and light weight. In this study author use resin as a attachment material, while supported cloth either woven or knitted were manufactured from amplified polypropylene filaments (BCF), and the they do the testing for tensile strength, resistance to bending, shear strength, resistance to penetration. Results is concluded from this study is woven fabric shown better mechanical properties than composite material produced from knitted fabric because of the knitted fabric distinct by the process of overlap between the stitches that gave better resistance

Modeling techniques for predicting the mechanical properties of woven fabric textile composites: A Review by Anurag Dixit, Harlal Singh Mali [4]. Researchers review the past and recent modelling techniques by both analytical and numerical. This research is related to the mechanical behaviour of textile-reinforced composites in general and woven fabric textile composites. The finite-element analysis of repeating unit cell geometry in addition with the homogenization technique proves very important for predicting the properties. The main aim of this study is not only to discuss the different modelling strategies and the mathematics involved, but also to provide the reader with an overview of the investigations conducted.

Fabrication of fixed polishing tool by knitting diamond/CNT fiber threads on cloth by Jing Zhou, Jing Lu, Zhiping Xue, and Xipeng Xu [5]. In this paper authors discuss knitting diamond/CNT fibre threads on cloth by novel polishing tool. Diamond particles are adhered to the surface of CNT fibres. They use heat treatment to fix diamond abrasives on the CNT fibres, and discuss the experimental parameters. By method of cross-stitch diamond/CNT fibre threads are knitted on cloth and evaluate the processing performance of polishing tool. Results are found form this study are reveal that the concentration of diamond solution and immersing time has great effect on the amount and uniformity of diamond on the surface of the fibre. When the concentration of diamond is $0.5 \mathrm{wt} . \%$ effect of adhesion get an ideal result and the immersing time is $5 \mathrm{~min}$. Diamond particles are bond with carbon nanotube fibres under heat treatment conditions, and the effect on the tensile strength of the fibre is observed. Proper heat treatment parameters make it reach to $168.74 \mathrm{Mpa}$ compared with the original's $83.35 \mathrm{Mpa}$, increased by $102.4 \%$. The fixed diamond abrasives polishing tool is used to process agalmatolite. Performance of the diamond tool is compared with polishing tool made of pristine carbon nanotube fibres, and results shows that the former has certain removal effect, and its wear resistance is better than the latter.

Sizing effects on the interfacial shear strength of a carbon fibre reinforced two-component thermoplastic polymer by Andreas Hendlmeiera, Lucas I. Marinovica, Salwan Al-Assafib, Filip Stojcevskia, Luke C. Hendersona [6]. In this study author discusses about carbon fibre reinforcement. Carbon fibre surface treatment conditions (current, bath 
conductivity, and sizing) gave a comprehensive set of 27 unique carbon fibre samples. They do the examinations for shears strength (IFSS) in a two-component polymethyl methacrylate resin via the $\mathrm{V}$-notch shear test. Epoxy-sized fibres show a strong dependence on surface treatments and were widely variable $(25.6 \pm 0.72$ to $38.5 \pm 2.69 \mathrm{MPa})$. These studies suggest that the epoxy sizing is soluble in the methyl methacrylate monomer and is removed from the surface before complete polymerisation. Adhesion in epoxy-sized fibres seemed linked to the ratio of oxygen and nitrogen on the fibre surface (determined by XPS). Polyamide-sized fibres possessed a smaller data variation $(37.3 \pm 3.34$ to $33.4 \pm 3.18 \mathrm{MPa})$, suggesting the polyamide-sizing masks the underlying surface chemistry of the fibre induced by the variations in surface treatment. When they use hybrid of these two results are comes with the polyurethane sized fibres $(36.1 \pm 2.19$ to $28.8 \pm 2.82 \mathrm{MPa})$.

Mechanical characterization of basalt woven fabric composites: numerical and experimental investigation by Piergiorgio Valentino, Emanuele Sgambitterra [7]. Authors do the experimental tests and numerical finite element (FE) simulations for basalt fabric composite, with different twill wave reinforcements, i.e. twill 2/2 and twill 1/3, have. Fabric reinforcement's show repeating undulations of warp and fill yarn, simple mixtures law. They take mesoscopic scale which is lying between the microscopic and the macroscopic, for the mechanically characterization of fabric reinforced composite. They do this study to evaluate the stiffness of a fabric reinforced composite in warp and fill direction. Numerical FE model is carried for elliptical sections and sinusoidal shape of the yarns, and experimental tests have been carried out in order to validate the proposed model. Authors experimentally investigate the strength and the failure modes of the composite material.

Analysis of the Mechanical Properties of Woven Fabrics from Glass and Basalt Yarns" by Stana Kovačević, Snježana Brnada, Polona DobnikDubrovski [8]. Technical fabrics are used for the purpose reinforcement of carbon fibre. These fibers have good mechanical properties. These fabrics are elongated during tensile stress in the direction of tensile force, and at the same time they contract crosswise in relation to the action of the tensile force. Researchers investigate the tensile properties of woven fabrics made from glass and basalt yarns. In this work measurements are taken after lateral contraction and from this Poisson's ratio is calculated. Upgraded innovative device of the strength tester and samples of fabrics of non-standard shapes (cross and square) are used. In order to define the impact of mechanical properties of the yarns from which the fabrics are made is analysed before and after weaving on them.

Characterization of mechanical behaviour of woven fabrics: Experimental methods and benchmark results" by J. Cao, R. Akkerman, P. Boisse, J. Chen, H.S. Cheng [9]. For the production of high specific-strength products textile composites made of woven fabrics have demonstrated excellent mechanical properties. Researchers make efforts in the woven fabric sheet forming are currently at a point where benchmarking will lead to major advances in understanding both the strengths and the limitations of existing experimental and modelling approaches. Results of the test provide valuable information for the material characterization and forming process design of woven composites. Trellis frame and bias extension tests are conducted for both balanced and unbalanced fabrics and compared to collaborative effort. Shear deformation is the dominative deformation mode for woven fabrics in forming. They observe the effects of testing variations on the results and the normalization methods, numerical modelling efforts can commence and develop new testing methods to advance the field. 


\section{Methodology}

i. Initially research paper relevant to the topic is gathered and after going through research papers, mechanical properties ofRegular carbon fabrics and woven fabricscomposite fibre

ii. A 3-D CAD model will be prepared by studying the conventional design of composite plates with woven fabrics and regular fabric model .

iii. Prepared 3-D model will be transferred to ANSYS software and proper meshing will be created on the model for further analysis.

iv. For determining the Static structural analysis will be performed on ANSYS. For studying structural analysis will be performed on the Regular carbon fabrics and woven fabricscomposite panel.

\section{Design}
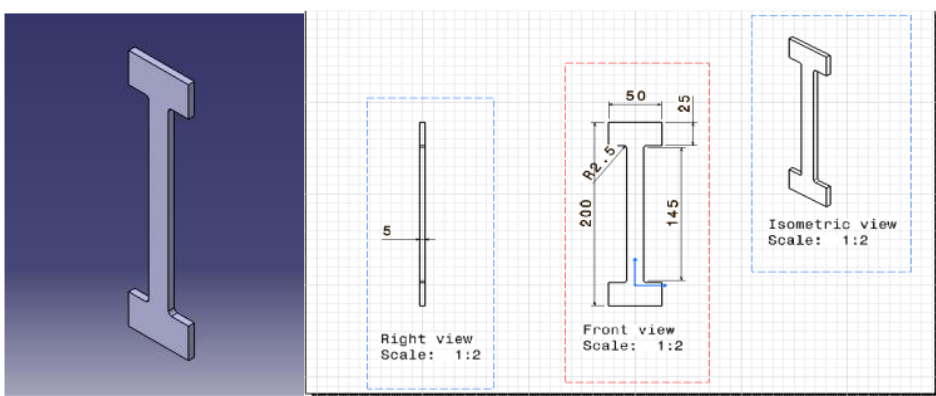

Figure 1: CATIA model and Drafting of carbon fibre specimen

\section{FEM Analysis for Regular Carbon Fabrics}

The finite element method (FEM), is a numerical method for solving problems of engineering and mathematical physics.

\subsection{Engineering Material - Regular Carbon Fibre}

\begin{tabular}{c|l|}
\hline$\square$ Ply Type & \\
\hline Type & Regular \\
\hline
\end{tabular}

Table 1: Details of engineering materials

\begin{tabular}{|c|c|c|c|c|}
\hline \multicolumn{5}{|c|}{ Properties of Outline Row 3: REGULAR CARBON FIBER } \\
\hline & A & B & & c \\
\hline 1 & Property. & Value & & Unit \\
\hline 2 & 8 Density & $1.49 \mathrm{E}-09$ & $m m^{\wedge}-3 t$ & \\
\hline 3 & 田柁 Orthotropic Secant Coefficient of Thermal & & & \\
\hline 8 & $\square$ Orthotropic Elasticity & & & \\
\hline 9 & Young's Modulus $\mathrm{X}$ direction & $1.21 E+05$ & MPa & \\
\hline 10 & Young's Modulus $Y$ direction & 8600 & MPa & \\
\hline 11 & Young's Modulus $Z$ direction & 8600 & MPa & \\
\hline 12 & Poisson's Ratio XY & 0.27 & & \\
\hline 13 & Poisson's Ratio YZ & 0.4 & & \\
\hline 14 & Poisson's Ratio $x z$ & 0.27 & & \\
\hline 15 & Shear Modulus XY & 4700 & MPa & \\
\hline 16 & Shear Modulus YZ & 3100 & MPa & \\
\hline 17 & Shear Modulus $x Z$ & 4700 & MPa & \\
\hline 18 & $\boxminus \oslash$ Orthotropic Stress Limits & & & \\
\hline 19 & Tensile $\mathrm{X}$ direction & 2231 & MPa & \\
\hline 20 & Tensile $Y$ direction & 29 & MPa & \\
\hline 21 & Tensile $\mathrm{Z}$ direction & 29 & MPa & \\
\hline 22 & Compressive $\mathrm{X}$ direction & -1082 & MPa & \\
\hline 23 & Compressive $Y$ direction & -100 & $\mathrm{MPa}$ & \\
\hline 24 & Compressive $\mathrm{Z}$ direction & -100 & MPa & \\
\hline 25 & Shear $X Y$ & 60 & MPa & \\
\hline 26 & Shear $\mathrm{YZ}$ & 32 & MPa & \\
\hline 27 & Shear $\mathrm{XZ}$ & 60 & MPa & \\
\hline
\end{tabular}




\subsection{Geometry}

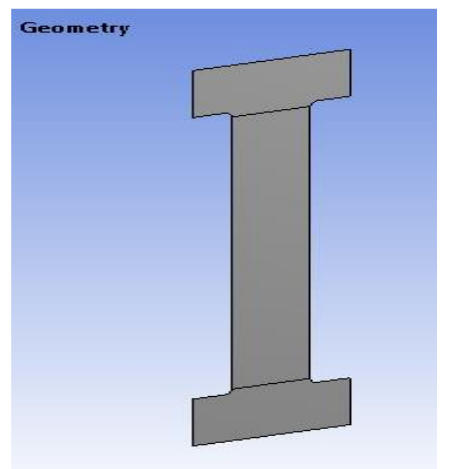

Figure 2: Geometry imported in ANSYS

\subsection{Mesh}

ANSYS Meshing is a general-purpose, intelligent, automated high-performance product. It produces the most appropriate mesh for accurate, efficient Multi physics solutions.

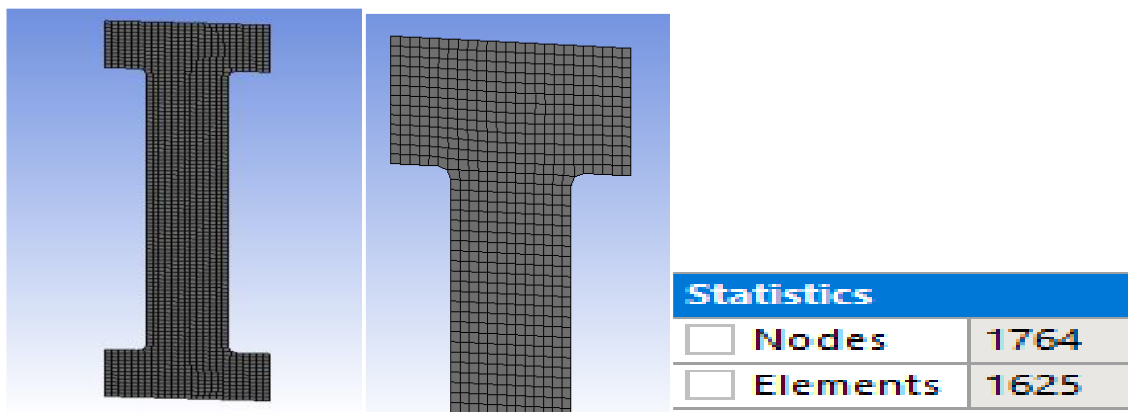

Figure 3: Details of meshing and geometric properties

\subsubsection{Ply Orientation}

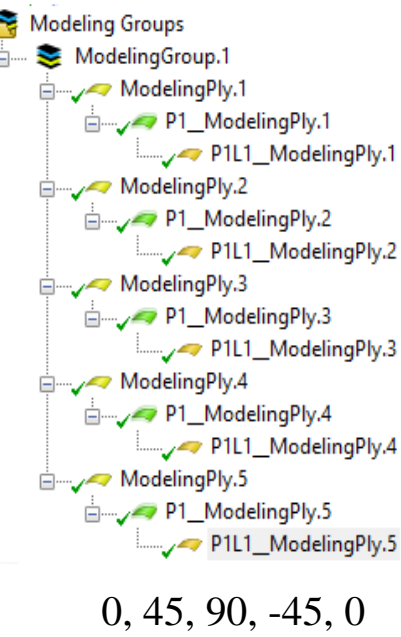

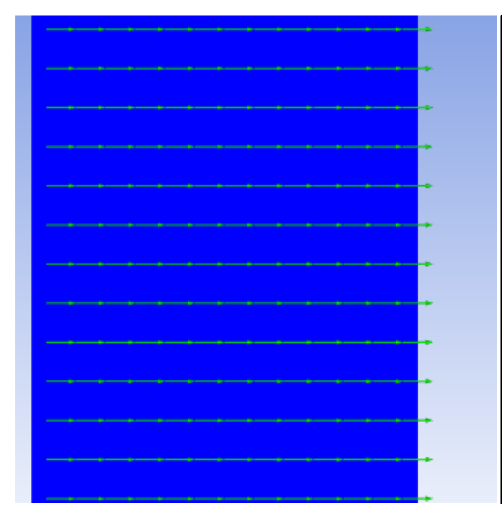

$0^{0}$ ply orientation

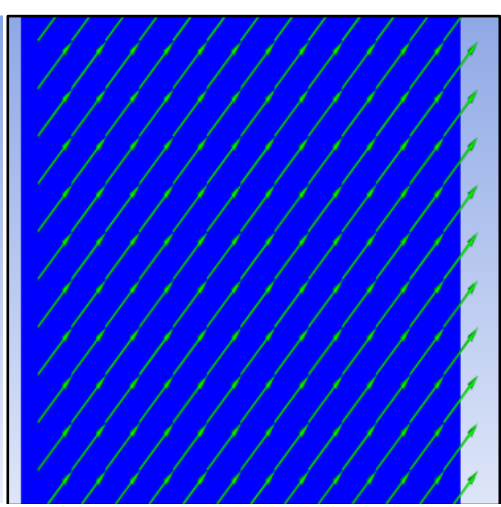

$45^{0}$ ply orientation 


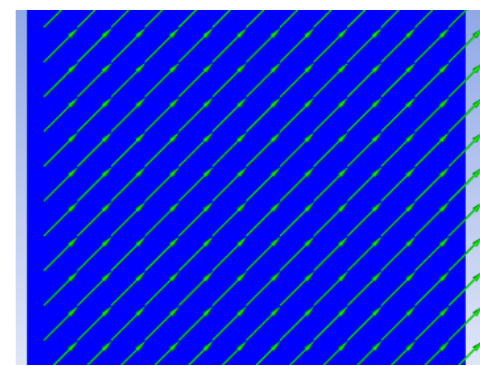

$90^{0}$ ply orientation

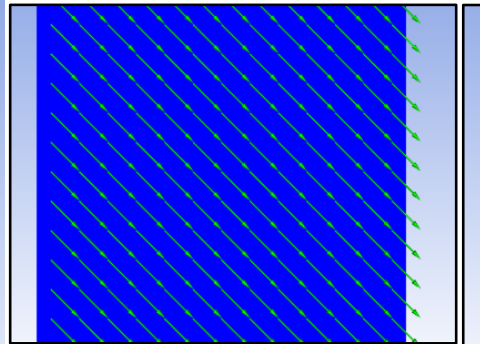

$-45^{0}$ ply orientation

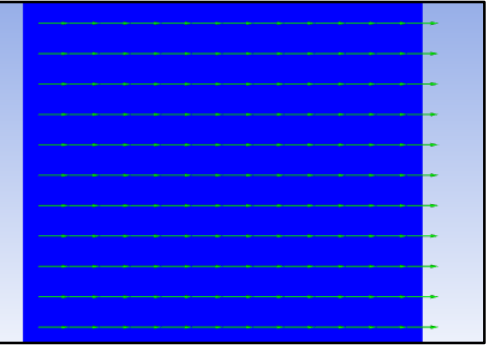

$0^{0}$ ply orientation

Figure 3:Different ply orientation

\subsection{Boundary Conditions}

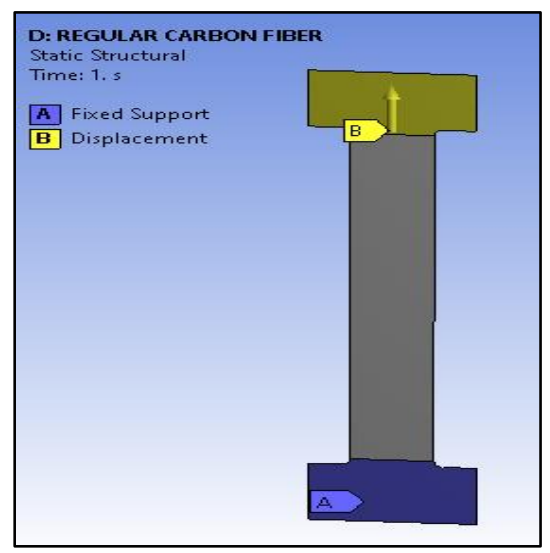

Figure 4: Details of boundary conditions

Fixed support is applied at base and displacement of $1 \mathrm{~mm}$ is applied to study stress results for different layers or ply orientation.

6.5. Total Deformation Results

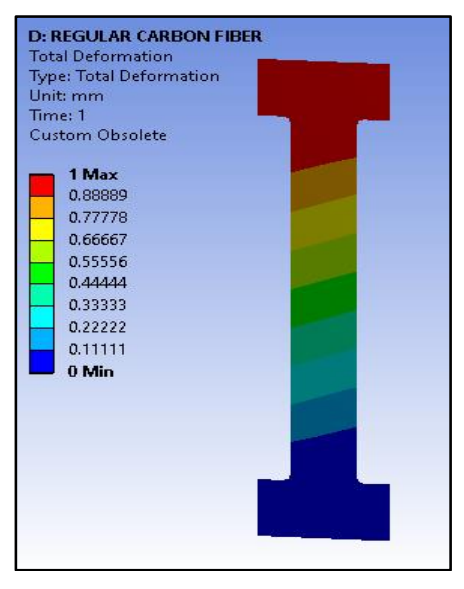

Figure 5: Total deformation results 
6.6. Equivalent Stress Results

Different stress plot has been plotted for different ply orientation

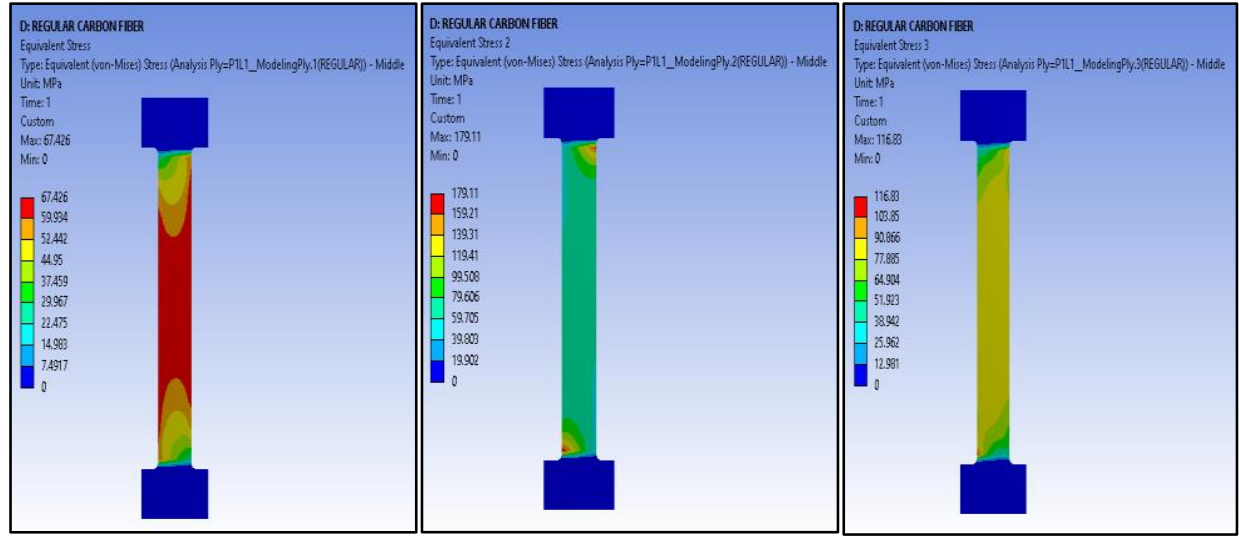

(1)

(2)

(3)

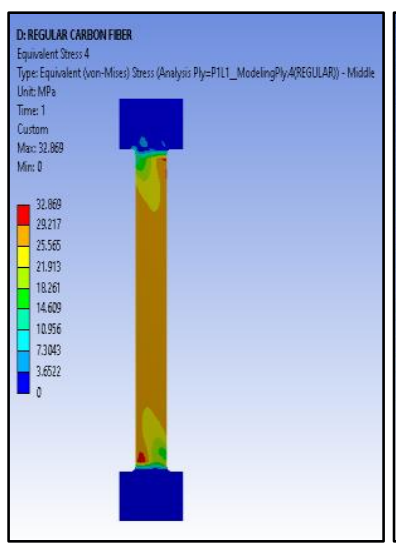

(4)

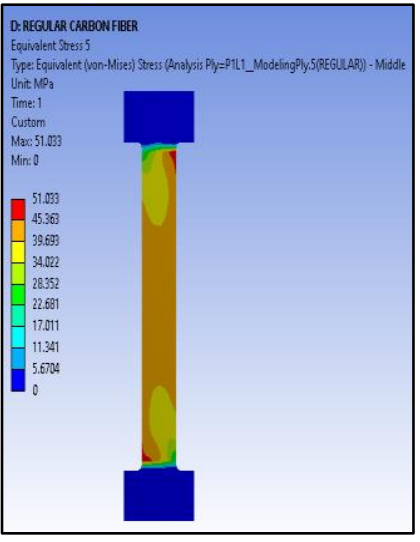

(5)

Figure 6: Equivalent stress results for regular carbon fiber

6.7. Reaction Force

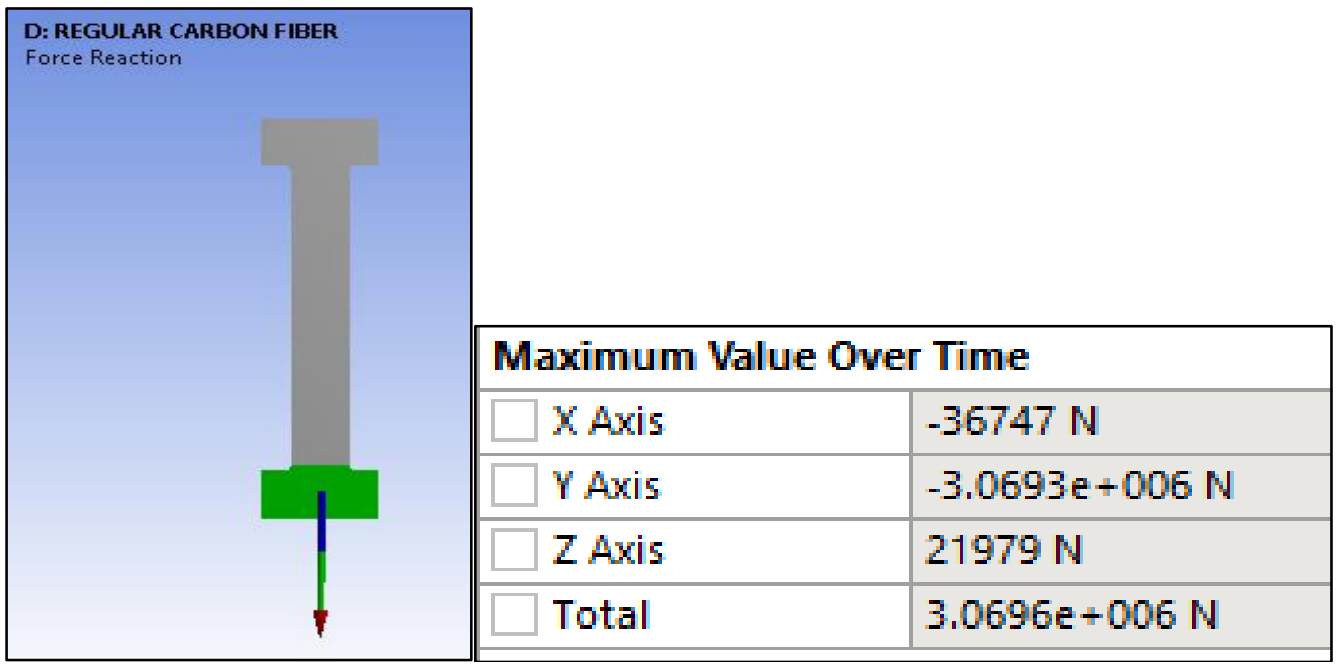

Figure 7: Reaction force 
Maximum reaction force observed to be around $3.06 \times 10^{6} \mathrm{~N}$.

\section{Geometry of woven carbon fibre sample}

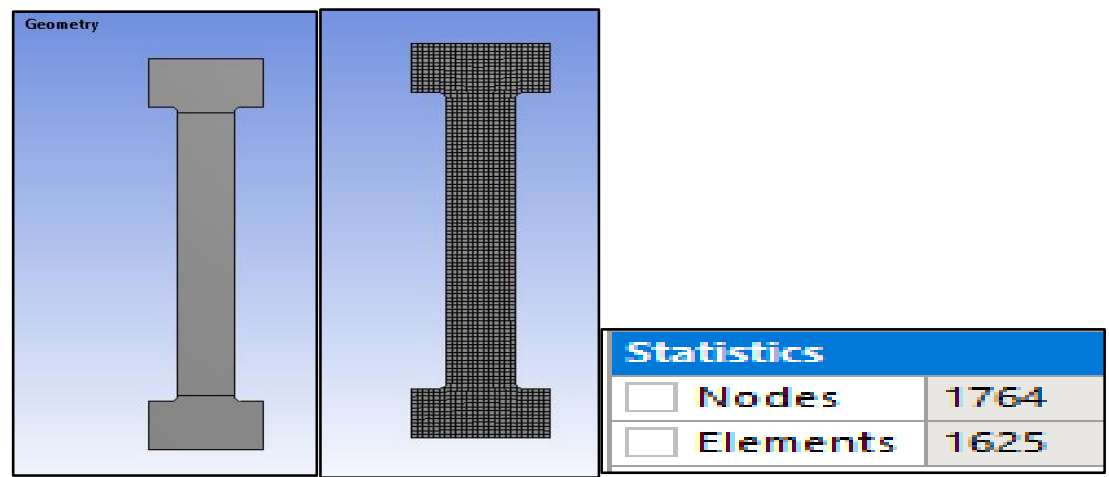

Figure 8: Details of geometry and meshing

7.1. Engineering data - woven carbon fibre

Table 2: Details of engineering materials

\begin{tabular}{|c|l||}
\hline Q Ply Type & \\
\hline Type & Woven \\
\hline \hline
\end{tabular}

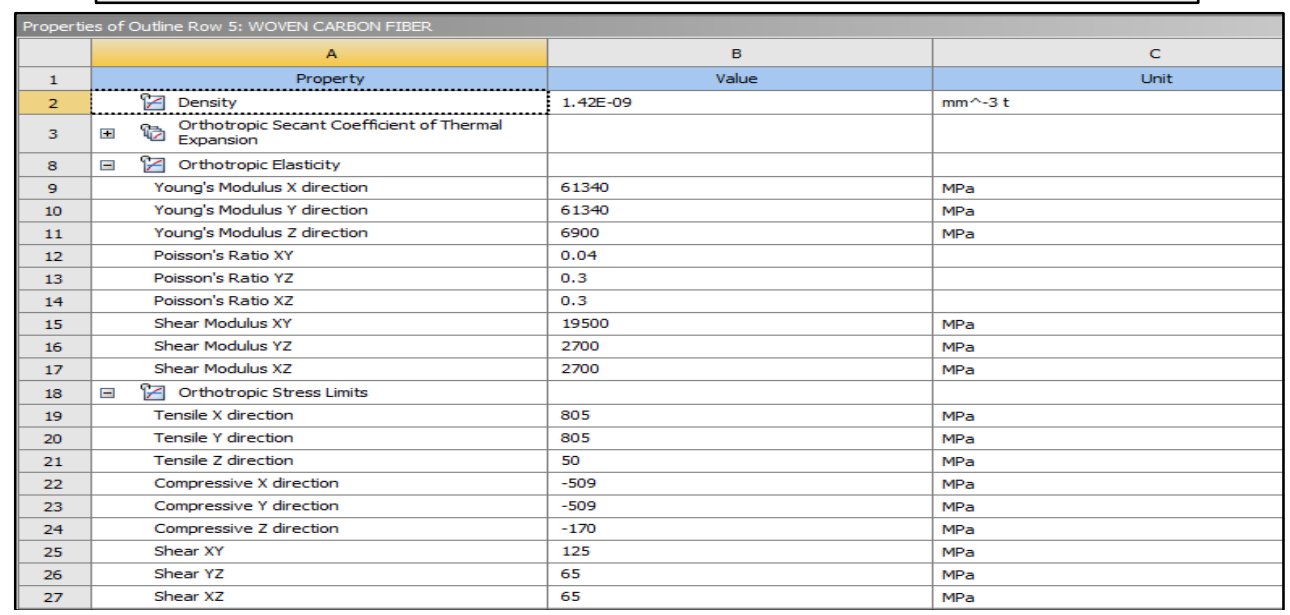

7.2. Boundary conditions

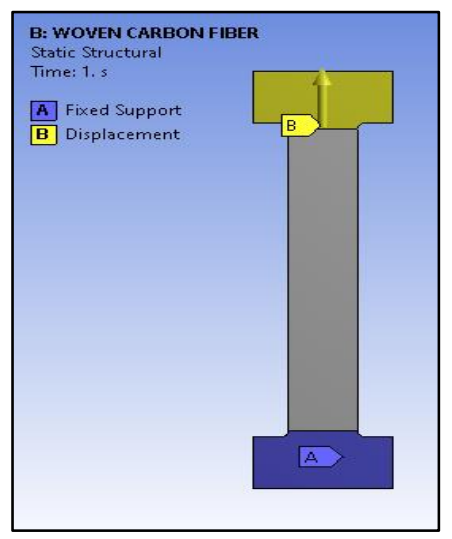

Figure10: Details of boundary conditions 
7.3. Equivalent stress results

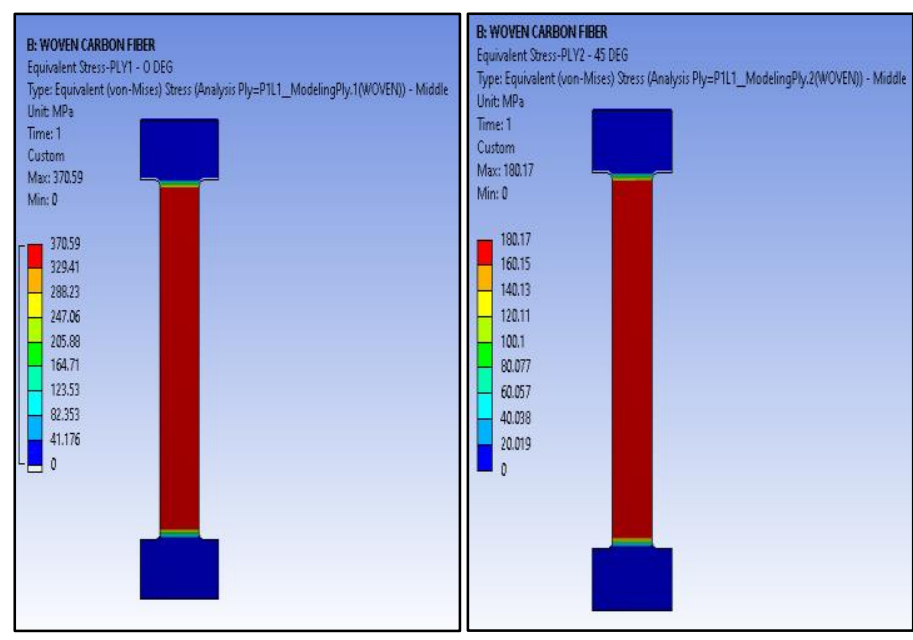

(1)
(2)

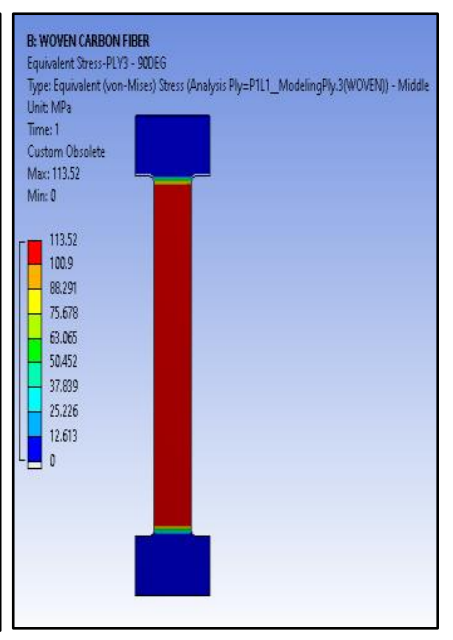

(3)

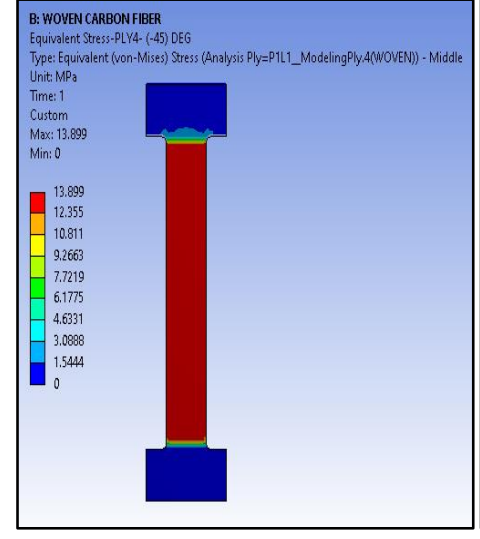

(4)

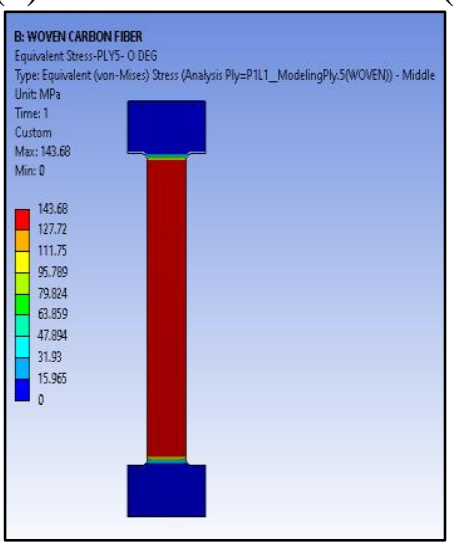

(5)

Figure 11:Equivalent stress results for woven carbon fibre

\subsection{Reaction force}

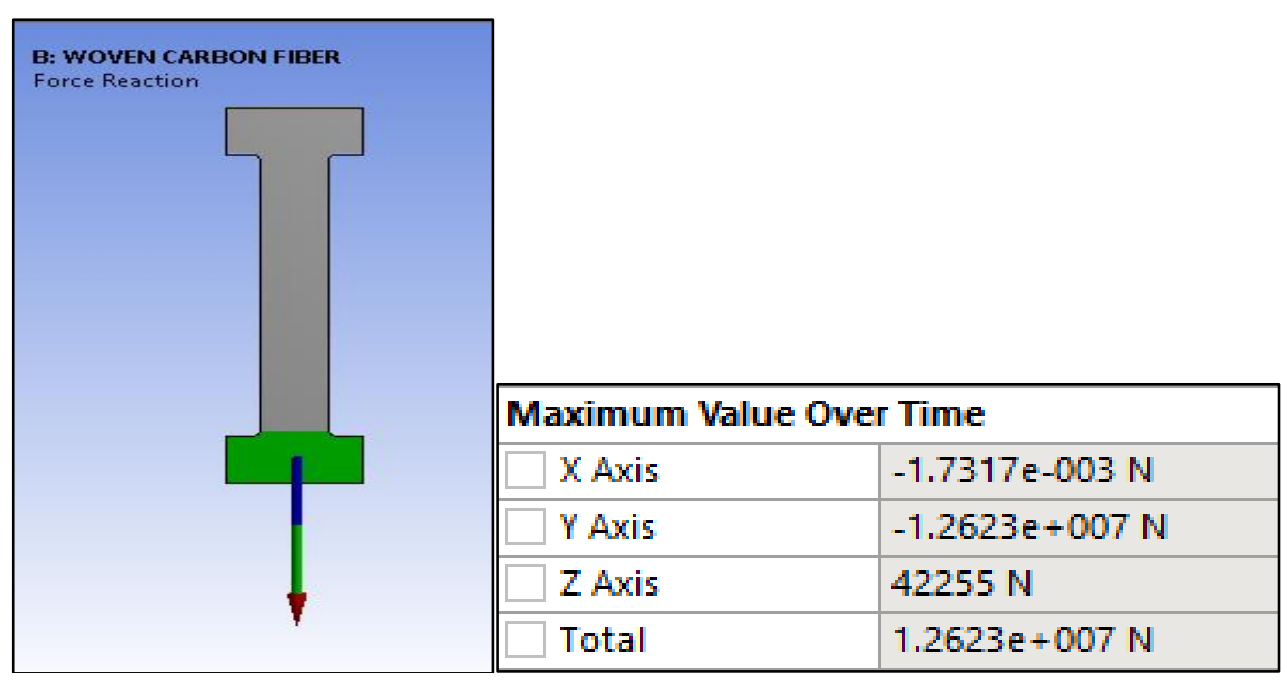

Figure 12: Details of force reaction of woven carbon fibre 
In present research changing the material woven fibre orientation induces reaction force of $1.26 \times 10^{7} \mathrm{~N}$. it is observed that woven carbon has more reaction force compared to regular carbon. $\mathrm{O}$, it is beneficial to use woven compared to existing regular orientation.

\section{Conclusion}

i. In present research two different regular and woven carbon fibre specimen are used and displacement of $1 \mathrm{~mm}$ is applied to obtain reaction force.

ii. It is observed from ANSYS results that with regular carbon fibre reaction force maximum reaction force observed to be around $3.06 \times 10^{6} \mathrm{~N}$.

iii. Similarly, for woven carbon fibre reaction force maximum reaction force observed to be around $1.26 \times 10^{7} \mathrm{~N}$.

iv. It is observed from results that woven carbon have more reaction strength to handle existing boundary conditions.

\section{References}

[1] Oliver Döbrich, Thomas Gereke, Chokri Cherif; Modeling the mechanical properties of textile-reinforced compositeswith a near micro-scale approach, Composite Structures 135 (2016) $1-7$

[2] M.Y. Matveev, A.C. Long, I.A. Jones; Modelling of textile composites with fibre strength variability, Composites Science and Technology 105 (2014) 44-50

[3] Karnoub A, Makhlouf S, Kadi N and Azari Z; Comparison Mechanical Properties for Fabric (Woven and Knitted) Supported by Composite Material, Textile SciEng 2015, 5:4

[4] Anurag Dixit, Harlal Singh Mali; Modeling techniques for predicting the mechanical properties of woven fabrictextile composites: A Review, Mechanics of Composite Materials, Vol. 49, No. 1, March, 2013 (Russian Original Vol. 49, No. 1, January-February, 2013)

[5] Jing Zhou, Jing Lu, Zhiping Xue, XipengXu, Fabrication of fixed polishing tool by knitting diamond/CNT fiber threads on cloth, S0925-9635(18)30618-6 https://doi.org/10.1016/j.diamond.2018.10.024DIAMAT 724128 October 2018

[6] Andreas Hendlmeiera, Lucas I. Marinovica, Salwan Al-Assafib, Filip Stojcevskia,Luke C. Hendersona, Sizing effects on the interfacial shear strength of a carbon fibre reinforced two-component thermoplastic polymer, Composites Part A 127 (2019) 105622

[7] Piergiorgio Valentino, Emanuele Sgambitterra, Franco Furgiuele, Marco Romano, Ingo Ehrlich, Norbert Gebbeken, Mechanical characterization of basalt woven fabric composites: numerical and experimental investigation; P. Valentino et alii, Fratturaed IntegritàStrutturale, 28 (2014) 1-11; DOI: 10.3221/IGF-ESIS.28.01

[8] Stana Kovačević, Snježana Brnada, Polona Dobnik Dubrovski, Analysis of the Mechanical Properties of Woven Fabrics from Glass and Basalt Yarns, DOI: 10.5604/12303666.1167424

[9] J. Cao, R. Akkerman, P. Boisse, J. Chen, H.S. Cheng, E.F. de Graaf, J.L. Gorczyca, P. Harrison, G. Hivet, J. Launay, W. Lee, L. Liu, S.V. Lomov, A. Long, E. de Luycker, F. Morestin, J. Padvoiskis, X.Q. Peng, J. Sherwood, Tz. Stoilova, X.M. Tao, I. Verpoest, A. Willems, J. Wiggers, T.X. Yu, B. Zhu, Characterization of mechanical behavior of woven fabrics: Experimental methods and benchmark results, DOI:10.1016/j.compositesa.2008.02.016 